\title{
PERANCANGAN KEY PERFORMANCE INDICATORS KINERJA SUPPLY CHAIN PT.XYZ DENGAN PENDEKATAN BALANCED SCORECARD
}

\author{
${ }^{1 \cdot}$ Joko Hardono, ${ }^{2} \cdot$ Henri Ponda \\ 1,2. Staff Pengajar Program Studi Teknik Industri, Fakultas Teknik \\ Universitas Muhammadiyah Tangerang \\ Jl. Perintis Kemerdekaan I/33, Cikokol, Kota Tangerang \\ Email : jhardno@yahoo.com, henri_ponda@umt.ac.id
}

\begin{abstract}
A b s t r a k
Supply Chain performance measurement PT.XYZ had only seen from the productivity of the Company. Productivity is only able to measure the performance of the internal process, while the internal process is but one link in the chain of Supply Chain. Companies need to design a model of supply chain performance measurement as a whole and integrated in a causal relationship, ranging from suppliers, internal processes to customers, in order to know the effectiveness of supply chain companies. Balanced scorecard meet the necessary perspective.
\end{abstract}

Balanced scorecard model is used as a framework for designing of Key Performance Indicator (KPI) of supply chain performance PT.XYZ. KPI is design based on 4 perspectives, that is : internal processes, customers, learning and growth and perspective financial. Weighting to determine priorities between perspective and KPI performed using Analytical Hierarchy Process (AHP).

Result from th eanalysis is generated $20 \mathrm{KPI}$. Internal process perspective contain 9 KPIs with total weight 21,0\%, Customer perspective contain $6 \mathrm{KPIs}$ with total weight 42,6\%, Learning and growth perspective contain 4 KPIs with total weight $17,5 \%$, Shareholder perspective contain 1 KPI with total weight 19,0.

Kata Kunci : Key Performance Indicatos, supply chain, balanced scorecard,. Analytical Hierarchy Process.

\section{PENDAHULUAN}

Tingkat penyebaran konsumen pada area yang cukup luas memerlukan waktu yang cukup lama bagi suatu produk untuk sampai dan digunakan oleh para konsumen. Hal ini menjadi masalah yang serius bagi jenis produk yang tidak tahan lama atau cepat rusak jika kontak langsung dengan udara, seperti aneka kue, roti, permen, snack, sabun, atau produk-produk yang tidak boleh kontak langsung dengan tangan manusia seperti obat-obatan, racun, dan berbagai jenis bahan kimia. Pengemasan dengan bahan paking dari plastik (plastic packaging) memberikan solusi terhadap permasalahan tersebut diatas.

PT.XYZ merupakan Perusahaan yang bergerak di bidang printing plastic packaging. Tingkat persainngan dan tuntutan pelanggan yang makin ketat mengharuskan Perusahaan untuk dapat memberikan produk tidak hanya berkualitas yang baik tetapi juga dalam waktu yang lebih cepat serta harga yang lebih kompetitif. Untuk mewujudkan tujuan Perusahaan tersebut, diperlukan adanya koordinasi lintas sektoral dari semua departemen atau organisasi yang terkait dalam suatu rantai penciptaan nilai mulai dari supplier, pabrik, jasa transportasi dan jaringan distribusi serta pelanggan.

Model pengelolaan rantai pasok yang mengintegrasikan pemasok, Perusahaan dan pelanggan yang banyak digunakan oleh Perusahaan adalah "Supply Chain Management"(SCM). Secara umum penerapan konsep SCM dalam Perusahaan akan memberikan manfaat, antara lain kepuasan pelanggan, meningkatkan pendapatan, menurunnya biaya, pemanfaatan asset yang semakin tinggi, peningkatan laba, dan Perusahaan semakin besar. (Jebarus,2001) 
Mengingat besarnya manfaat SCM dalam pengendalian sebuah bisnis, maka pada jurnal ilmiah ini akan membahas tentang Perancangan Key Performnace Indicator (KPI) kinerja Supply Chain Perusahaan dengan pendekatan model Balanced Scorecard. Perancangan dilakukan dengan pengembangan indikator-indikator yang meliputi kinerja pada sepanjang aliran rantai suplai dengan pendekatan perspektif Balanced Scorecard, yaitu : internal proses, pertumbuhan dan pembelajaran, pelanggan dan finansial.

Indikator kinerja yang selama ini digunakan untuk mengukur kinerja Supply Chain PT.XYZ hanya dilihat dari sisi produktivitas Perusahaan. Pendekatan pengukuran seperti ini tergolong dalam model pengukuran tradisional. (Neely at. al.,1995 dalam Chan dan Qi, 2003). Produktivitas hanya merupakan indikator kinerja pada bagian internal proses, sedangkan internal proses hanyalah merupakan salah satu mata rantai dari Supply Chain. Menurut (Lee dan Billington, 1992 dalam Gunasekaran et. Al, 2004) menyebutkan bahwa pengukuran kinerja yang dilkukan secara parsial hanya pada sisi internal proses saja tidak akan memberikan hasil yang effisien.

Jadi kelemahan dari penerapan kinerja inti selama ini yang diterapkan oleh PT.XYZ adalah jika dalam penerapan pengukuran kinerja ditemukan adanya indikasi permasalahan, maka akan sangat sulit bagi manager untuk mengembangkan suatu model hubungan sebab akibat dalam penyelesaiannya. Ini karena tidak cukup tersedia data-data atau informasi yang dapat digunakan untuk menganalisa kemungkinan penyebab permasalahan tersebut. Perusahaan perlu merancang suatu model KPI supply chain secara keseluruhan dan terintegrasi dalam suatu hubungan sebab akibat, mulai dari supplier, internal proses hingga konsumen, agar dapat diketahui efektifitas pelaksanaan supply chain Perusahaan.

\section{METODE PENELITIAN}

Model pendekatan yang digunakan dalam perancangan key performance Indicators Supply Chain ini adalah metode Balanced Scorecard. Dari model tersebut disusun metrik-metrik indikator kinerja supply chain. Penetepan hirarki dan pembobotan dari metrik-metrik tersebut dilakukan dengan menggunakan metode Analytic Hierarchy Process.

Metode pengumpulan data dalam penyusunan jurnal ilmiah ini antara lain :

\section{Studi Lapangan}

Studi lapangan dilakukan untuk mengetahui kondisi sebenarnya di lapangan. Disini dilakukan wawancara, kuesioner dan brainstorming dengan pihak manajemen PT XYZ mengenai indikator kinerja supply chain yang di lakukan Perusahaan saat ini.

\section{Studi Pustaka}

Studi pustaka dilakukan untuk mendapatkan landasan teori yang akan menjadi acuan berpikir pelaksanaan kegiatan penelitian ini. Studi pustaka di peroleh dari berbagai literatur antara lain buku, website, jurnal-jurnal penelitian sejenis yang telah dilakukan sebelumnya.

\section{HASIL DAN PEMBAHASAN}

\section{A. Maping Sistem Supply Chain}

Mapping dilakukan untuk menggambarkan supply chain Perusahaan sehingga dapat diketahui sistem yang berjalan mengenai lima proses inti supply chain,yaitu plan, source,make, deliver dan return. Selain itu juga dapat di ketahui departemen-departemen (perusahaan-perusahaan) yang terkait di dalamnya dan juga aliran material, informasi dan uang. Gambar 2 adalah maping SCM PT XYZ. 


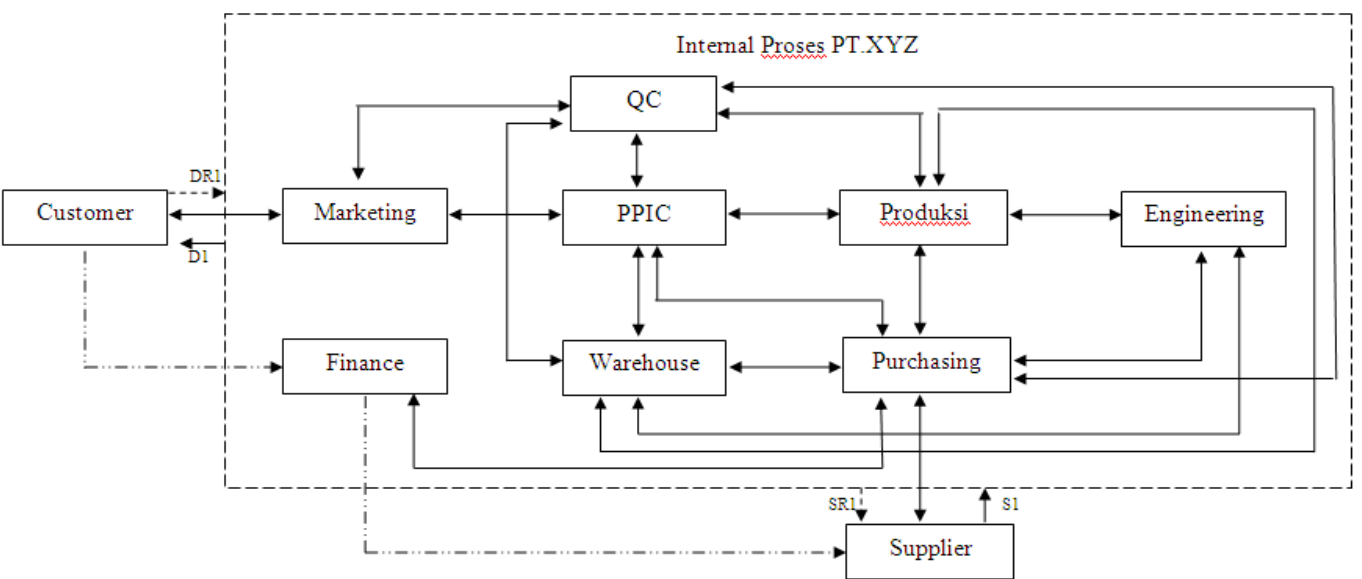

Gambar 1. Mapping SCM PT. XYZ

B. Mengidentifikasi Key Performance Indikator (KPI)

Tahap ini penulis mengidentifikasi KPI-KPI yang akan di gunakan sebagai ukuran keberhasilan. Identifikasi dilakukan terhadap KPI proses inti dari supply chain yaitu, KPI supplier, KPI internal,. KPI costumer, KPI financial. Dari hasil studi literatur seperti buku, jurnal, ulasan dari website serta brainstorming dengan manajemen Perusahaan teridentifikasi 24 KPI dalam 4 perspektif indikator SCM sebagai berikut :

\section{a. Perspektif Supplier facing}

1. Prosentase material reject

2. Supplier cycle time

3. Supplier delivery performance

4. Respon terhadap material retur

b. Internal Facing

1. Production waste

2. Cost of Good Sold

3. Productivity (meter/man-hours)

4. Inventory days of supply

5. Overall Efectiveness Equipment (OEE)

6. Prosentase turnover karyawan

7. Jumlah kecelakaan kerja

8. Jumlah jam training per karyawan

9. Tingkat ketidakhadiran karyawan.

c. Customer Facing

1. Posentase produk retur

2. Order fulfillment lead time

3. Delivery performance

4. Respon terhadap produk return

5. Respon terhadap keluhan pelanggan

6. New Customer

7. Customer Retention

8. Index kepuasan pelanggan

d. Shareholder Facing

1. EBIT

2. ROTA

3. EVA

\section{Validasi KPI}

Identifikasi yang telah penulis buat kemudian dilakukan validasi terhadap pihak Perusahaan. Validasi dilakukan dengan melalui penyebaran kuesioner ke Perusahaan dalam hal ini adalah PT.XYZ. Kuesioner dilakukan dengan sample purposive berjumlah 25 karyawan. Format yang digunakan untuk kuesioner menggunakan format linkert, Hasil kuesioner ini berupa validasi (persetujuan atau ketidaksetujuan) terhadap identifikasi KPI yang penulis ajukan serta kemungkinan tambahan KPI baru. 
Untuk mengukur validitas hasil kuesioner digunakan metode Product Moment Correlation Pearson (r). Rumus korelasi product moment adalah sebagai berikut:

$r=\frac{\mathrm{N} \sum \mathrm{XY}-\left(\sum \mathrm{X}\right)\left(\sum \mathrm{Y}\right)}{\sqrt{\mathrm{N} \sum \mathrm{X}^{2}-\left(\sum \mathrm{X}\right)^{2}} \sqrt{\mathrm{N} \sum \mathrm{Y}^{2}-\left(\sum \mathrm{Y}\right)^{2}}} \ldots \ldots \ldots \ldots . . .1$ (Mulyono, 2007)

Dimana :

$\mathrm{X}=$ skor individual

$\mathrm{Y}=$ total skor untuk masing-masing responden.

$\mathrm{N}$ = adalah jumlah responden/data pengamatan

Pengujian reliabilitas digunakan rumus Rulon, yaitu dengan membandingkan varians perbedaan skor dengan varians total, adapun rumusnya adalah sebagai berikut :

$r_{x x \prime}=1-\frac{S D b^{2}}{S D t^{2}}$ .2 (Mulyono, 2007)

$\mathrm{rxx}^{\prime} \quad=$ Koefisien reliabilitas

$\mathrm{SDb} 2=$ Varians perbedaan skor belahan

SDt2 = Varians skor Total.

Rumus untuk menhitung varians adalah sebagai berikut :

$S D x^{2}=\frac{\sum X^{2}-\frac{\left(\sum X\right)^{2}}{N}}{N} \ldots \ldots \ldots \ldots . . . . . .3($ Mulyono, 2007)

KPI hasil validasi dan reliability adalah sebagi berikut :

a. Perspektif Supplier facing

1. Prosentase material reject

2. Supplier cycle time

3. Supplier delivery performance

b. Internal Facing

1. Production waste

2. Cost of Good Sold

3. Productivity (meter/man-hours)

4. Inventory days of supply

5. Overall Efectiveness Equipment (OEE)

6. Prosentase turnover karyawan

7. Jumlah kecelakaan kerja

8. Jumlah jam training per karyawan

9. Tingkat ketidakhadiran karyawan.

10. Aged Inventory

c. Customer Facing

1. Posentase produk retur

2. Delivery performance

3. Respon terhadap produk return

4. New Customer

5. Customer Retention

6. Index kepuasan pelanggan

d. Shareholder Facing

4. EBIT

JIM, Vol. 3, No. 1, Januari 2018, pp.1-10 
Hasil validasi menunjukkan adanya pengurangan jumlah KPI menjadi 20 KPI dari rancangan yang diajukan sebelumnya sebanyak 24 KPI. KPI yang dihilangkan adalah respon terhadap keluhan pelanggan, Order fulfillment lead time, ROTA dan EVA.

\section{Kerangka kerja Supply Chain}

Desain kerangka kerja Suppply chain .PT.XYZ seperti pada gambar 3 Keberhasilan supply chain dalam mencapai tujuannya antara lain menekan rejek, memperkecil cycle time, menurunkan aged inventory, meninkatkan produktifitas, akan berimbas secara internal yaitu menurunkan tingkat pemborosan sehingga akan meningkatkan pendapatan Perusahaan dan secara ekternal akan memberikan nilai tambah kepada pelanggan yang berupa kualitas produk yang baik, serta delivery yang tepat waktu.

Keuntungan yang dirasakan pelanggan akan mempengaruhi tingkat kepuasan pelanggan, sehingga Perusahaan akan dapat mempertahankan pelanggan atau bahkan bertambah jumlah pelanggan baru. Hal ini akan membawa konsekuensi logis pada peningkatan penjualan Perusahaan sehingga pendapatan Perusahaan akan meningkat.

Perbaikan finansial yang dialami oleh Perusahaan sebagai akibat dari tercapainya tujuan supply chain serta kepuasan pelanggan akan memotivasi Perusahaan untuk selalu melakukan proses perbaikan.



Gambar 2. Kerangka Kerja Supply Chain PT. XYZ

\section{E. Kerangka kerja Balanced Scorecard}

Ada keterkaitan yang kuat antara kerangka kerja supply chain dengan kerangka kerja balanced scorecard. Desain kerangka kerja balanced scorecard PT.XYZ seperti pada gambar 3.

Perspektif pelanggan menggunakan ukuran berapa nilai yang diberikan kepada pelanggan dilihat dari segi waktu, kualitas, performansi layanan, dan biaya. Untuk mencapai tujuan ini dilakukan melalui perbaikan pada pespektif internal proses juga perspektif pertumbuhan dan pembelajaran. 
Perspektif internal Business process digunakan untuk mengevaluasi seberapa besar tingkat ekspektasi yang diharapkan pelanggan serta shareholder dapat terpenuhi melalui perbaikan proses di internal organisasi tersebut. Untuk mencapai tujuan ini perlu didukung oleh perbaikan ada perspektif pertumbuhan dan pembelajaran.

\section{F. Tahap Pembobotan}

Tahap pembobotan ini dilakukan dengan Analytical Hierarchy Process (AHP), adapun langkah-langkahnya sebagai berikut :

a. Melakukan perbandingan berpasangan antar KPI.

b. Menghitung bobot dan ratio konsistensi.

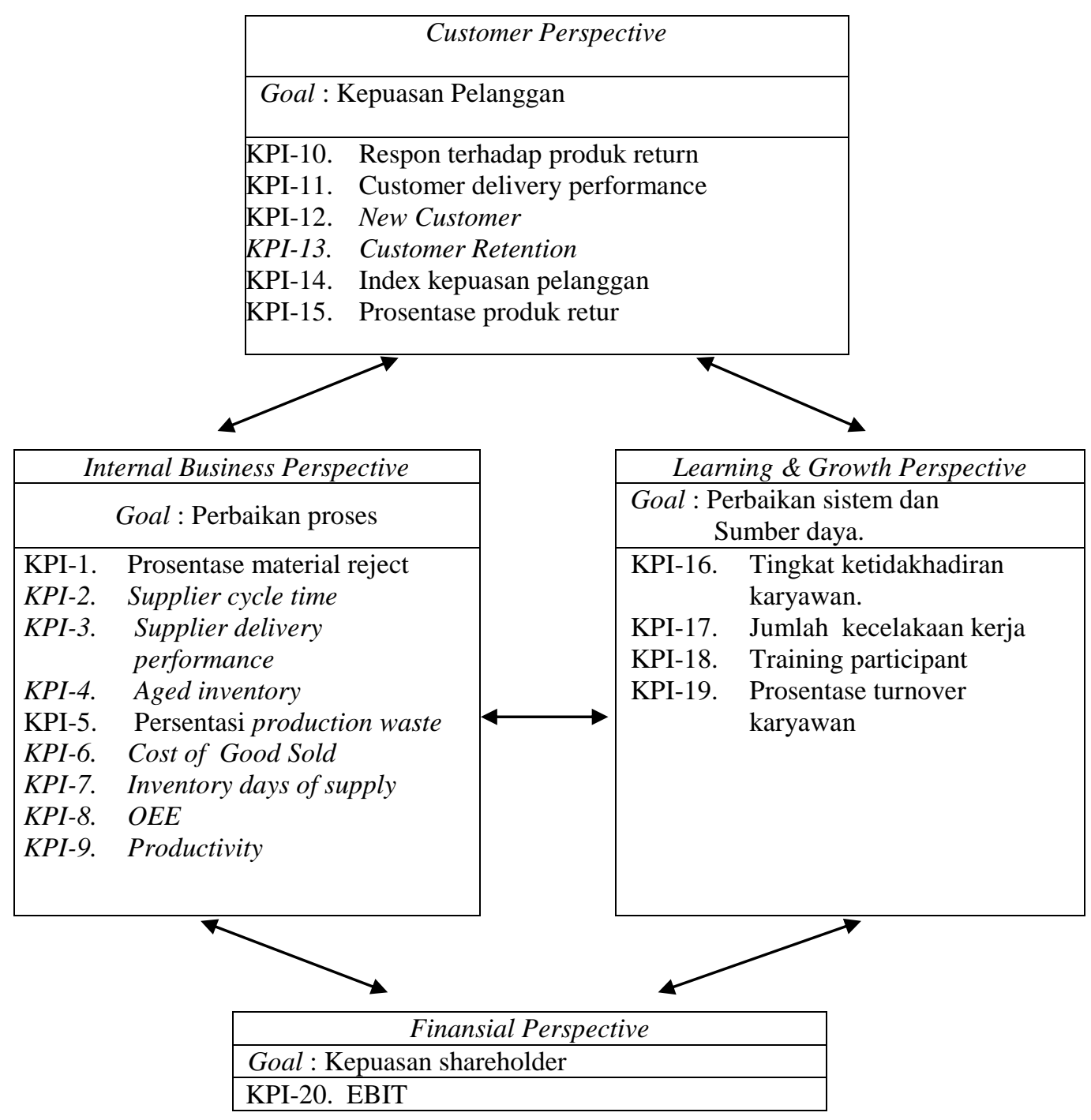

Gambar 3. Kerangka kerja balanced scorecard PT.XYZ

\section{a. Melakukan perbandingan berpasangan antar KPI}

Untuk memudahkan pemahaman, misalkan jumlah elemen yang dipasangkan ada empat buah, maka matrix perbandingan berpasangan sebagai berikut :

Tabel 1 Matrix perbandingan berpasangan

\begin{tabular}{|c|c|c|c|c|}
\hline Kriteria atau Alternatif & 1 & 2 & 3 & 4 \\
\hline 1 & $\mathrm{X}_{11}$ & $\mathrm{X}_{12}$ & $\mathrm{X}_{13}$ & $\mathrm{X}_{14}$ \\
\hline 2 & $\mathrm{X}_{21}$ & $\mathrm{X}_{22}$ & $\mathrm{X}_{23}$ & $\mathrm{X}_{24}$ \\
\hline 3 & $\mathrm{X}_{31}$ & $\mathrm{X}_{32}$ & $\mathrm{X}_{33}$ & $\mathrm{X}_{34}$ \\
\hline 4 & $\mathrm{X}_{41}$ & $\mathrm{X}_{42}$ & $\mathrm{X}_{43}$ & $\mathrm{X}_{44}$ \\
\hline
\end{tabular}

JIM, Vol. 3, No. 1, Januari 2018, pp.1-10 
Xij adalah skor individual perbandingan berpasanga kriteria $\mathrm{i}$ terhadap kriteria $\mathrm{j}$.

Untuk mengisi matrik perbandingan berpasangan itu, digunakan bilangan untuk menggambarkan relatif pentingnya suatu elemen di atas yang lainnya, berkenaan dengan sifat tersebut. Tabel 2 memuat skala perbandingan berpasangan.

Tabel 2 Skala dasar pada perbandingan berpasangan (Marimin, 2004)

\begin{tabular}{|c|c|c|}
\hline $\begin{array}{l}\text { Tingkat } \\
\text { Kepentingan }\end{array}$ & Penjelasan & Keterangan \\
\hline 1 & Kedua elemen sama pentingnya & $\begin{array}{l}\text { Dua elemen mempunyai pengaruh yang } \\
\text { sama besar terhadap tujuan. }\end{array}$ \\
\hline 3 & $\begin{array}{l}\text { Elemen yang satu sedikit lebih } \\
\text { penting dari elemen lainnya }\end{array}$ & $\begin{array}{c}\text { Pengalaman dan penilaian sedikit } \\
\text { menyokong satu elemen dibandingkan } \\
\text { elemen lainnya. }\end{array}$ \\
\hline 5 & $\begin{array}{l}\text { Elemen yang satu lebih penting } \\
\text { dari elemen lainnya }\end{array}$ & $\begin{array}{l}\text { Pengalaman dan penilaian sangat kuat } \\
\text { menyokong satu elemen dibandingkan } \\
\text { elemen lainnya. }\end{array}$ \\
\hline 7 & $\begin{array}{l}\text { Elemen yang satu sangat lebih } \\
\text { penting dari elemen lainnya }\end{array}$ & $\begin{array}{l}\text { Satu elemen yang kuat disokong dan } \\
\text { dominan terlihat dalam praktek }\end{array}$ \\
\hline 9 & $\begin{array}{l}\text { Elemen yang satu mutlak lebih } \\
\text { penting dari yang lain }\end{array}$ & $\begin{array}{c}\text { Bukti yang mendukung elemen yang satu } \\
\text { terhadap elemen yang lain memiliki } \\
\text { tingkat penegasan tertinggi yang mungkin } \\
\text { menguatkan }\end{array}$ \\
\hline $2,4,6,8$ & $\begin{array}{l}\text { Apabila ragu - ragu antara dua } \\
\text { nilai yang berdekatan. }\end{array}$ & $\begin{array}{l}\text { Nilai ini diberikan bila ada dua kompromi } \\
\text { di antara pilihan }\end{array}$ \\
\hline $1 /(1-9)$ & $\begin{array}{l}\text { Kebalikan nilai tingkat } \\
\text { kepentingan dari skala } 1-9 .\end{array}$ & \\
\hline Kebalikan & \multicolumn{2}{|c|}{$\begin{array}{l}\text { Jika untuk aktivitas mendapatkan satu angka dibanding dengan aktivitas } \mathrm{j} \text {, } \\
\text { maka j mempunyai nilai kebalikannya disbanding dengan } \mathrm{i}\end{array}$} \\
\hline
\end{tabular}

Skala itu mendefinisikan dan menjelaskan nilai 1 sampai dengan 9 yang ditetapkan bagi pertimbangan dalam membandingkan pasangan elemen yang sejenis di setiap tingkat hirarki terhadap suatu kinerja yang berada setingkat di atasnya.

Untuk memperoleh peringkat prioritas menyeluruh bagi suatu persoalan keputusan, kita harus menyatukan atau mensitesis pertimbangan yang dibuat dalam melakukan perbandingan berpasangan yaitu dengan melakukan suatu pembobotan untuk menunjukan prioritas setiap elemen.

\section{c. Menghitung bobot}

Hasil pengisian perbandingan berpasangan kemudian diolah untuk menentukan bobot pada setiap kriteria dalam menentukan alternatif keputusan. Suatu pendekatan alternatif yang sederhana untuk memperoleh prioritas menggunakan langkah-langkah berikut (Mulyono ,2007) :

1. Hitung jumlah total nilai perbandingan setiap kolom $\left(\square \mathbf{X}_{\mathbf{i j}}\right)$ 
Tabel 3. Menghitung nilai $\sum X_{i j}$

\begin{tabular}{|c|c|c|c|c|}
\hline $\begin{array}{c}\text { Kriteria atau } \\
\text { Alternatif }\end{array}$ & 1 & 2 & 3 & 4 \\
\hline 1 & $\mathrm{X}_{11}$ & $\mathrm{X}_{12}$ & $\mathrm{X}_{13}$ & $\mathrm{X}_{14}$ \\
\hline 2 & $\mathrm{X}_{21}$ & $\mathrm{X}_{22}$ & $\mathrm{X}_{23}$ & $\mathrm{X}_{24}$ \\
\hline 3 & $\mathrm{X}_{31}$ & $\mathrm{X}_{32}$ & $\mathrm{X}_{33}$ & $\mathrm{X}_{34}$ \\
\hline 4 & $\mathrm{X}_{41}$ & $\mathrm{X}_{42}$ & $\mathrm{X}_{43}$ & $\mathrm{X}_{44}$ \\
\hline Total & $\Sigma \mathrm{X}_{\mathrm{i} 1}$ & $\Sigma \mathrm{X}_{\mathrm{i} 2}$ & $\Sigma \mathrm{X}_{\mathrm{i} 3}$ & $\Sigma \mathrm{X}_{\mathrm{i} 4}$ \\
\hline
\end{tabular}

2. Hitung jumlah rasio antara $\mathrm{Xij}: \Sigma \mathrm{X}_{\mathrm{i} 1}$ dan selanjutnya hitung rata-rata nilai pada setiap baris. Nilai inilah yang menjadi bobot prioritas setiap kriteria atau alternatif

Tabel 4 Menghitung nilai Bobot Prioritas (Sriyono, 2007)

\begin{tabular}{|c|c|c|c|c|c|}
\hline $\begin{array}{c}\text { Kriteria atau } \\
\text { Alternatif }\end{array}$ & 1 & 2 & 3 & 4 & $\begin{array}{c}\text { Rata-Rata (Bobot } \\
\text { Prioritas) }\end{array}$ \\
\hline 1 & $\frac{\mathrm{X}_{11}}{\sum \mathrm{X}_{\mathrm{i} 1}}$ & $\frac{X_{12}}{\sum X_{i 2}}$ & $\frac{X_{13}}{\sum X_{i 3}}$ & $\frac{X_{14}}{\sum X_{i 4}}$ & $\mathrm{P} 1$ \\
\hline 2 & $\frac{\mathrm{X}_{21}}{\sum \mathrm{X}_{\mathrm{i} 1}}$ & $\frac{X_{22}}{\sum X_{i 2}}$ & $\frac{X_{23}}{\sum X_{i 3}}$ & $\frac{X_{24}}{\sum X_{i 4}}$ & $\mathrm{P} 2$ \\
\hline 3 & $\frac{\mathrm{X}_{31}}{\sum \mathrm{X}_{\mathrm{i} 1}}$ & $\frac{X_{32}}{\sum X_{i 2}}$ & $\frac{X_{33}}{\sum X_{i 3}}$ & $\frac{X_{34}}{\sum X_{i 4}}$ & $\mathrm{P} 3$ \\
\hline 4 & $\frac{\mathrm{X}_{41}}{\sum \mathrm{X}_{\mathrm{i} 1}}$ & $\frac{\mathrm{X}_{33}}{\sum \mathrm{X}_{\mathrm{i} 2}}$ & $\frac{\mathrm{X}_{43}}{\sum \mathrm{X}_{\mathrm{i} 3}}$ & $\frac{\mathrm{X}_{44}}{\sum \mathrm{X}_{\mathrm{i} 4}}$ & $\mathrm{P} 4$ \\
\hline
\end{tabular}

Dimana :

$\mathrm{P} \quad=$ Rata-rata bobot criteria

Dari hasil perhitungan bobot untuk masing-masing perspektif Balanced Scorecard serta KPI yang bersesuaian adalah seperti pada tabel 5

Tabel 5 Bobot Perspective dan KPI

\begin{tabular}{|c|l|}
\hline Perspektif (Bobot-\%) & \multicolumn{1}{|c|}{ KPI (bobot-\%) } \\
\hline & KPI-1 (0.8) \\
& KPI-2 (1.1) \\
& KPI-3 (1.4) \\
& KPI-4 (2.7) \\
Internal (21.0) & KPI-5 (3.0) \\
& KPI-6 (2.4) \\
& KPI-7 (2.4) \\
& KPI-8 $(2.8)$ \\
& KPI-9 (4.2) \\
\hline & KPI-10 (2.9) \\
& KPI-11 (7.7) \\
& KPI-12 (3.5) \\
Customer (42.6) & KPI-13 (4.5) \\
& KPI-14 (13.3) \\
& KPI-15 (11.1) \\
\hline Learning \& growth (17.5) & KPI-16 $(2.1)$ \\
\hline
\end{tabular}




\begin{tabular}{|l|l|}
\hline & KPI-17 (2.8) \\
& KPI-18 (5.9) \\
& KPI-19 (6.6) \\
\hline Shareholder $(19.0)$ & KPI-20 (19.0) \\
\hline
\end{tabular}

\section{KESIMPULAN}

Dari hasil analisa dan pembahasan dapat disimpulkan bahwa :

1. Identifikasi KPI Supply Chain PT XYZ dilakukan melalui studi literatur seperti buku, jurnal, ulasan dari website serta brainstorming dengan manajemen Perusahaan. Hasil identifikasi teridentifikasi 24 KPI dalam 4 perspektif indikator SCM .

2. Dari 24 KPI yang teridentifikasi diuji validitasnya dengan metode Product Moment Correlation Pearson (r), serta dikaukan pengujian reliabilitas dengan menggunakan rumus Rulon. Hasil validasi menunjukkan adanya pengurangan jumlah KPI menjadi 20 KPI. KPI yang dihilangkan adalah respon terhadap keluhan pelanggan, Order fulfillment lead time, ROTA dan EVA.

3. Dari 20 KPI yang lolos uji validasi dilakukan pembobotan dengan metode Analitycal Hierarchy Process $(A H P)$. Hasil pembototan adalah sebagai berikut :

\begin{tabular}{|l|l|}
\hline Perspektif (Bobot-\%) & KPI (bobot-\%) \\
\hline & KPI-1 (0.8) \\
& KPI-2 (1.1) \\
& KPI-3 (1.4) \\
KPI-4 (2.7) \\
& KPI-5 (3.0) \\
& KPI-6 (2.4) \\
& KPI-7 (2.4) \\
& KPI-8 (2.8) \\
& KPI-9 (4.2) \\
\hline & KPI-10 (2.9) \\
& KPI-11 (7.7) \\
& KPI-12 (3.5) \\
Customer (42.6) & KPI-13 (4.5) \\
& KPI-14 (13.3) \\
& KPI-15 (11.1) \\
\hline \multirow{3}{*}{ Learning \& growth (17.5) } & KPI-16 (2.1) \\
& KPI-17 (2.8) \\
& KPI-18 (5.9) \\
& KPI-19 (6.6) \\
\hline Shareholder (19.0) & KPI-20 (19.0) \\
\hline
\end{tabular}

\section{SARAN}

Untuk mengetahui KPI mana yang perlu diprioritaskan dalam perbaikan kinerjanya, maka dilakukan pengelompokan KPI berdasarkan bobot dan skornya, sehingga perlu dilakukan pengukuran performansi dari masing-masing KPI tersebut untuk mendapatkan skor-nya. Dari hasil perhitungan pembobotan diperoleh :

a. Bobot tinggi yaitu perspektif indicator customer yaitu 0.426

b. Bobot sedang yaitu perspektif indicator internal yaitu 0,209

c. Bobot rendah yaitu perspektif indicator learning and growth dan perspektif financial masingmasing 0.175 dan 0.19

Setelah bobot dan skor dari masing masing KPI diketahui maka bisa dibutkan skala priorotas KPI berdasarkan matrik Bobot-Skor sebagi berikut : 


\begin{tabular}{|l|l|l|l|}
\hline \multirow{2}{*}{ Bobot } & \multicolumn{3}{|c|}{ Skor } \\
\cline { 2 - 4 } & Tinggi & Sedang & Rendah \\
\hline Tinggi & & & \\
\hline Sedang & & & \\
\hline Rendah & & & \\
\hline
\end{tabular}

\section{DAFTAR PUSTAKA}

Bozarth dan Handfield, (2008), "Introduction To Operations And Supply Chain Management", Pearson Education, Inc., New Jersey, United State.

Brewer dan Speh, (2000),'Using Balanced Scorecard to Measure Supply Chain Performance", ABI/INFORM Global, Jurnal Of Business Logistic Vol.21, No.1, 2000

Budiarti,. (2007), "Evaluasi Kinerja Bisnis Dengan Pendekata Balanced Scorecard Pada PT.Poliplas Makmur Santosa Ungaran.,Skripsi”, FE Jurusan Akutansi, Semarang.

Dianawati dan Panggalo, (2009)," Pengukuran Dan Analisis Nialai Overall Equipment Efectiveness Sebagai Dasar Perbaikan Sistem Manufacture Pipa Baja", Jurusan Mesin dan Industri FT UGM, ISBN 978-979-18528-1-4, Yogyakarta

Erni, (2009); "Productivity Measurement Using Omax and Fuzzy Logic at PT.AMD.”,Industrial Engineering Department. Indonusa Esa Unggul University, Indonesia

Gunasekaran, at al(2004); "A Framework For Supply Chain Performance Measurement", Int.J.Production Economic.87, Arkansas, USA. 